\title{
ЗАВЕРШАЮЩИЙ ЭТАП СОЗДАНИЯ ЕДИНОГО ЭНЕРГЕТИЧЕСКОГО РЫНКА ЕС: КОГДА ЖЕСТКОСТЬ ЗАЛОГ УСПЕХА
}

\begin{abstract}
Аннотация: В статье рассматривается вызывающая в последнее время неподдельный интерес практика Европейской комиссии и Суда Европейского Союза по реализации и воплощению в жизнь положений Энергопакетов (главным образом, Третьего энергопакета) с той целью, чтобы подчеркнуть первостепенную роль Комиссии и Суда ЕС в деле строительства единого европейского энергетического рынка на его завершающем этапе. Автор преследует цель показать, как Комиссия в тесном взаимодействии с Судом ЕС использует имеющиеся у нее в распоряжении средства принуждения по отношению к государствам и компаниям в иелях выполнения ими своих обязательств в срере энергетики. Автор подробно описывает ряд дел как против энергокомпаний, так и в отношении государств-членов EC, инициированных Комиссией, часть из которых дошла до Суда ЕС. В заключение делается вывод о том, что именно жесткий подход Европейской комиссии и принципиальные позиции Суда ЕС при толковании положений законодательства ЕС в сфере энергетики есть основополагающая составляющая успеха в деле создания единого внутреннего энергетического рынка ЕС в 2014 году.
\end{abstract}

Ключевые слова: Европейский Союз, ТЭП, имплементация, конкуренция, энергетический рынок, Еврокомиссия, Третий энергопакет, либерализация, государства-члены ЕС, энергетические компании. DOI: 10.7256/1994-1471.2014.5.10762

$\mathrm{E}$ вропейский Союз (далее - ЕС, Евросоюз) дает много интересных и подчас поучительных примеров в отношении того, как надо действовать в той или иной ситуации. Одно из качеств ЕС, которому можно просто позавидовать, - умение ставить цели и непреклонно достигать их, используя целый набор принудительных мер. В ситуации кризиса европейской экономики такой жесткий подход становится просто необходимым и вполне оправданным условием выживания. Особенно если это касается европейского энергетического рынка - фундамента европейской экономики.

Старт глобальной «перестройке» энергетического рынка ЕС был дан принятием по инициативе Еврокомиссии (далее - Комиссия) поочерёдно трех энергопакетов для создания единого энергетического рынка. Концептуальной основой этого рынка стала по-своему революционная идея о необходимости постепенной либерализации энергетического рынка: отказ от модели естественных монополий и всемерное развитие конкуренции в тех секторах, которые до этого считались абсолютно неприкасаемыми. Все это следовало сделать, несмотря на сопротивление государств-членов Евросоюза, для которых естественные монополии в сфере энергетики всегда воспринимались, с одной стороны, как символ национального суверенитета, а, с другой стороны, как бездонная кормушка.

Последний Третий энергопакет (далее ТЭП) ${ }^{1}$ вступил в силу 3 сентября 2009 года, став

ТЭП состоит из 2 директив и 3 Регламентов: Directive 2009/72/EC of the European Parliament and of the Council of July,13,2009, concerning common rules for the internal market in electricity and repealing Directive 2003/54/EC// Official Journal of the European Union (OJ), No: L 211/55, 14/8/2009); Regulation (EC) No 714/2009 of the European Parliament and of the Council of July,13,2009 on conditions for access to the network for cross-border exchanges in electricity and repealing Regulations (EC) No 1228/2003// Official Journal of the European Union (OJ), No: L 211/15, 14/8/2009; Directive 2009/73/EC of the European Parliament and of the Council of July,13,2009, concerning common rules for the internal market in natural gas and repealing Directive 2003/55/EC//Official Journal of the European Union (OJ), No: L 211/55, 14/8/2009; Regulation (EC) No 715/2009 of the European Parliament and of the Council of July,13,2009 on conditions for access to the natural gas transmission networks and repealing Regulations (EC) No 1775/2005//Official Journal of the European Union (OJ), No: L 211/36, 14/8/2009; Regulation (EC) No 713/2009 of the European Parliament and of the Council of July,13,2009 establishing an Agency for the Cooperation of Energy Regulators//Official Journal of the European Union (OJ), No: L 211/1, 14/8/2009.

(C) Двенадцатова Татьяна Ивановна

* Аспирантка кафедры международного права, Московский государственный университет им. М.В. Ломоносова

[12ovatania@mail.ru]

119991, Россия, г. Москва, ГСП-1, Ленинские горы, д. 1, корп. 13-14 (4-й учебный корпус). 
формально финальным шагом в деле создания единого внутреннего энергорынка, которое должно быть завершено в 2014 г. В самом общем виде ТЭП использует следующие правовые инструменты интеграции национальных рынков газа и электроэнергии.

Во-первых, на национальном и на европейском уровнях создается единая европейская энергетическая сеть, в основу функционирования которой заложен принцип планирования и сотрудничества.

Во-вторых, учреждается Агентство по сотрудничеству энергетических регуляторов с широкими консультативными и рядом надзорных полномочий.

В-третьих, предусматривается разработка унифицированных правил трансграничной транспортировки газа и электроэнергии и одновременно создание наднационального оператора системы транспортировки.

В-четвертых, поставлена цель из так называемого «уязвимого потребителя» ("vulnerable consumer") сделать потребителя инициативного, за которым должно оставаться последнее слово при выборе поставщика газа и электроэнергии на основе максимально широких прав на получение необходимой для этого информации.

Такая возможность появляется у потребителя в результате реализации остальных еще более радикальных новелл ТЭП, которые включают в себя открытие рынков (market opening); предоставление недискриминационного доступа третьим лицам к системам транспортировки энергии и газа (third parties access); разъединение на уровне права собственности национальных естественных монополий, функционировавших до этого в форме вертикально интегрированных энергетических предприятий (unbundling), а также отход от государственного регулирования цен в сфере энергетики ${ }^{2}$.

Стоит ли говорить насколько велико значение и достижение целей либерализации и создания единого энергорынка, когда потребитель получит право выбирать для себя наиболее выгодные тарифы и условия обслуживания, когда все заинтересованные компании получат возможность свободно оказывать услуги по всей территории ЕС и устанавливать цены за свои услуги, исходя из реальной ситуации, сложившейся на рынке, когда начнется

См.: Communication from the Commission to the European Parliament, the Council, the European economic and social committee and the committee of the regions. Making the internal energy market work. Brussels, 15.11.2012, COM (2012) 663 final, P. 2//http://eur-lex. europa.eu/LexUriServ/LexUriServ.do?uri=COM:2012:0663 :FIN:EN:PDF. рост инвестиций в сферу энергетики, что повлечет за собой увеличение объемов и безопасность поставок энергии ${ }^{3}$.

Однако достижение планируемых целей в установленные сроки оказалось процессом достаточно сложным, так как различия в подходах к энергетике в странах ЕС остаются весьма значительными. В этой ситуации требование адаптировать национальное законодательство в рамках ТЭП неизбежно вызвало столкновение общеевропейских приоритетов и национальных интересов. Здесь становится понятно, отчего большинство стран Евросоюза не торопятся имплементировать ТЭП полностью: ведь чем глубже европейский финансовый кризис и очевиднее противоречия между государствами ЕС, тем меньше они хотят «размывать» свои национальные границы в таком чувствительном секторе, как энергетика, отдавая решение этих вопросов на откуп союзным структурам либо неким уполномоченным органам ${ }^{4}$.

В этой ситуации Комиссия оказалась вынуждена по максимуму задействовать все имеющиеся у нее контрольные и надзорные полномочия как по всемерному внедрению конкуренции в энергетический рынок, так и в отношении исполнения государствами своих обязательств в рамках ТЭП ${ }^{5}$ В связи с этим

Более подробно обзор глобальных изменений в структуре и законодательстве ЕС в сфере энергетики см.: Исполинов А.С., Двенадцатова Т.И. Создание единого энергетического рынка в ЕС: тихая революция с громкими последствиями//Балтийский регион. 2013. №2. URL:http://cyberleninka.ru/article/n/sozdanieedinogo-energeticheskogo-rynka-es-tihaya-revolyutsiya-sgromkimi-posledstviyami,

4 См.: Мельникова С. И. Два года сомнительного существования Третьего Энергопакета EC//http://www. eriras.ru/files/s-melnikova-dva-goda-somnitelnogo-

sushhestvovaniya-tretego-energopaketa-es.pdf.

Активность Комиссии вызвана прежде всего тем, что после принятия Регламента 1/2003 (Council Regulation (EC) No 1/2003 of 16 December 2002 on the implementation of the rules on competition laid down in Articles 81 and 82 of the Treaty//Official Journal of the European Communities.4.1.2003//http://eur-lex.europa. eu/LexUriServ/LexUriServ.do?uri=OJ:L:2003:001:0001:0

025:EN:PDF), получившего название «Постановление о модернизации», Еврокомиссия получила широкий инструментарий в свои руки по проведению расследований и наложению санкций. Комиссия получила право проводить расследования, в том числе касающиеся определенных типов соглашений и различных секторов, проводить любые проверки в рамках данных расследований. Кроме того, Европейская Комиссия согласно Регламенту имеет полномочия накладывать санкции и применять иные меры принуждения, в случае выявления нарушений конкуренции, причем это может быть и разовый штраф до $10 \%$ от общего оборота, и периодические штрафные платежи (длящийся штраф) до 5\% от среднедневного оборота компании. Таким образом, после реформы Комиссия получила обширные пол- 
интересно будет рассмотреть, как Комиссия в тесном взаимодействии с Судом ЕС использует имеющиеся у нее в распоряжении средства принуждения по отношению к государствам и компаниям в целях выполнения ими своих обязательств в сфере энергетики.

Контроль со стороны Комиссии в отношении государств-членов ЕС.

1. Проблема своевременного завершения имплементации ТЭП.

Как известно, имплементация Третьего энергопакета в законодательство государствчленов ЕС должна быть завершена до 2014 года, однако большинство стран не уложилось в этот срок. Более того, ряд государств ЕС до настоящего момента все еще не имплементировали и Второй энергопакет, хотя должны были это сделать в 2011 году. Именно поэтому выражение «трудное внедрение» как нельзя верно характеризует процедуру имплементации положений как Второго, так и Третьего энергопакетов ${ }^{6}$. Сложившаяся ситуация объясняется довольно просто: требуется время для того, чтобы изменить устоявшееся не за один день представление о том, что именно государство должно контролировать энергетику как стратегически важную отрасль экономики. На практике оказалось, что процесс передачи части полномочий государств на уровень ЕС в этом чувствительном секторе экономики, равно как и внедрение конкуренции туда, где ранее безраздельно правили бал национальные естественные монополии, крайне болезненно воспринимается на национальном уровне.

Тем не менее последние годы под «нажимом» Комиссии процесс имплементации пошел более активно ${ }^{7}$. Комиссия вовсе не собирается отказываться от идеи завершить создание единого рынка к концу 2014 г., хотя и признает, что на пути к этому возникли значительные затруднения.

Следуя идее, что стартовавшая либерализация должна проводиться одновременно в масштабах всего Евросоюза, Комиссия стала

номочия, достаточные для осуществления детального расследования возможных нарушений в области права конкуренции, а антимонопольные органы государствчленов Европейского Союза стали выполнять роль своего рода агентов Комиссии.

См.: Мельникова С. И. Два года сомнительного существования Третьего Энергопакета EC//http://www. eriras.ru/files/s-melnikova-dva-goda-somnitelnogosushhestvovaniya-tretego-energopaketa-es.pdf.

На конец февраля 2013 года, согласно данным Комиссии, ряд стран приняли положения ТЭП частично, некоторые из них имплементировали ТЭП, но сделали это с нарушениями. Комиссия активно ведет разбирательства, ряд дел уже переданы в Суд ЕС//см. подробнеe: http://www.ec.europa.eu. активно бороться с проблемой асимметричности имплементации государствами-членами EC положений ТЭП, так как несвоевременная имплементация приводит к различной степени открытости национальных энергетических рынков, искажению конкуренции и ситуации фрагментарности рынка. В соответствии с новыми полномочиями, данными ей Лиссабонским договором ${ }^{8}$, вступившим в силу в 2009 году, в случае нарушения обязательств по имплементации норм ЕС во внутреннее право в установленные сроки, Комиссия теперь может обратиться в Суд ЕС не только для того, чтобы признать сам факт нарушения, но и с целью применения Судом ЕС денежных санкций за это нарушение. Это дает Комиссии серьезные дополнительные рычаги по принуждению государств к выполнению положений законодательства ЕС в сфере энергетики.

В настоящее время Комиссия расследует в первоочередном порядке дела в отношении тех государств-членов, которые до сих пор полностью не имплементировали ТЭП или сделали это неправильно. Так, с сентября 2011г. Еврокомиссия инициировала 19 дел, связанных с несвоевременной имплементацией. Из этих дел к октябрю 2012 г. было закрыто только 12, а по остальным делам процедура расследования продолжается 9 . В период с 2012 по 2013 гг. Комиссия активно направляла мотивированные заключения государствам с целью добиться приведения национального законодательства в соответствие требованиям ТЭП ${ }^{10}$. За несвоевременную имплементацию директив Третьего энергопакета Польшей, Финляндией, Словенией, Болгарией и Великобританией ${ }^{11}$ Комиссия обратилась в Суд ЕС, поставив вопрос о несвоевременной имплементации директив Третьего энергопакета ${ }^{12}$. Особенно по-

8 См.: Лиссабонский договор, изменяющий Договор о Европейском Союзе и Договор об учреждении Европейского Сообщества от 13 декабря 2007 г. 2007/C 306/01// http://eulaw.ru/treaties/lisbon\#1.

9 См.: Table 12 in Staff Working Document entitled Energy Markets in the European Union in 2011/"SWD 1" part 4.

10 См.: MEMO/13/122, MEMO/13/375// доступно на: http http://ec.europa.eu/index_en.htm.

11 См.: European Commission Press Release 21.11.2012 "Internal energy market: Commission refers Poland and Finland to Court for failing to fully transpose EU rules" IP/12/1236//http://ec.europa.eu/eu_law/infringements/_ en.htm; European Commission Press Release 24.10.2012 "Internal energy market: Commission refers Poland and Slovenia to Court for failing to fully transpose EU rules" IP/12/1139. Доступно на:http://ec.europa.eu/eu_law/ infringements/_en.htm.

12 См.: European Commission Press Release, Brussels, 24 January 2013, Internal energy market: Commission refers Bulgaria, Estonia and the United Kingdom to Court for 
казательно упорство, с которым сопротивляется принятию как Второго, так и Третьего пакетов Великобритания, газовый рынок которой один из самых развитых и ликвидных. За неисполнение обязательств по имплементации в установленные сроки Комиссия попросила Суд ЕС установить для Великобритании пеню в размере 148 177, 92 евро за каждый день просрочки ${ }^{13}$ !

В аналогичную ситуацию попала и Румыния, которая и вовсе не приступала к имплементации ТЭП и пока только частично имплементировала в свое национальное законодательство положения директив Второго энергопакета, хотя должна была это сделать до 3 марта 2011г. Ответ на это со стороны Комиссии не заставил себя ждать. Комиссия ЕС в очередной раз напомнила, что задержки в имплементации негативно сказываются на всех участниках единого энергетического рынка, при этом больше всего страдают потребители, принцип защиты прав которых красной нитью проходит через все три энергопакета и является принципиальным для Комиссии. Отсюда и следующие цифры ${ }^{14}:$ за каждую директиву, которая не была имплементирована полностью либо в части, запрошенная Комиссией у Суда ЕС ЕЖЕДНЕВНАЯ пеня для Румынии составляет 30228,48 евро $^{15}$.

Нужно ли говорить, что ряд расследований, инициированных Комиссией, были закрыты еще до обращения Комиссии в Суд ЕС (дела против Испании, Швеции, Нидерландов $\left.{ }^{16}\right)$,

failing to fully transpose EU rules, IP/13/42, IP/12/1139, IP/12/1236, IP/13/42, IP/13/260// http http://ec.europa.eu/ index_en.htm.

13 Для сравнения: ежедневная пеня в отношении Болгарии составила 8448 евро, для Эстонии 4224 евро за газовую и 5068,8 евро за электрическую директивы соответственно.

14 См.: European Commission Press Release, Brussels, 21 March 2013.Internal energy market: Commission refers Romania to Court for failing to fully transpose EU rules. IP/13/260//доступно на: http http://ec.europa.eu/index_ en.htm.

15 В мае 2011 года Комиссия потребовала у Португалии привести в соответствие свое внутреннее законодательство, касающееся регулируемых потребительских цен на газ, в соответствии с законодательством ЕС. Нарушение со стороны Португалии выражалось в том, что среди прочих потребителей португальское законодательство все еще выделяло малые и средние предприятия или домохозяйства, которым поставка газа осуществлялась по регулируемым государством ценам. Причем в перспективе Португалия не планировала постепенную отмену подобных мер или их пересмотр. См. подробнее: IP/11/590 15.05.2011 Energy: Commission asks Portugal to change its end-user price regulation scheme to ensure freedom of choice and protection for consumers// http://ec.europa.eu/eu_law/index_en.htm.

16 См.: МЕMO/13/122//доступно на: http http:// ec.europa.eu/index_en.htm. что означает лишь одно - государства начинают осознавать все негативные финансовые последствия ${ }^{17}$ в случае передачи дела в Суд и стремятся избежать этого уже на стадии проведения расследования Комиссией.

Таким образом, налицо новые рычаги воздействия, которые есть в распоряжении Комиссии для обеспечения скорейшей имплементации и своевременного завершения создания единого энергорынка, которые она ловко и пока довольно удачно использует, обеспечивая тем самым жесткий мониторинг процесса имплементации законодательства о внутреннем энергетическом рынке государствами-членами ЕС. Это лишь подчеркивает всю критичность ситуации для «выживания» экономики EC, а также то, насколько важен в этой ситуации для ЕС в целом энергетический сектор.

2. Усилия Комиссии и Суда ЕС по устранению государственного регулирования цен на энергию.

Несмотря на то, что многие государствачлены ЕС уже смогли отойти от государственного регулирования ценообразования на газ и электричество, включая розничное потребление, ряд государств всё еще пытаются регулировать цены на энергию на розничном рынке. Комиссия уже возбудила ряд расследований в отношении тех государств-членов, которые устанавливают цены для потребителей и целых отраслей промышленности.

В этом отношении весьма показательно ставшее прецедентным и вызвавшее немало дискуссий решение Суда ЕС по делу Federutility ${ }^{18}$, в котором Суд ЕС, отвечая на запрос итальянского суда, заявил, что государственное регулирование цен на электроэнергию может быть оправданным только в строго определенных случаях: а) когда это необходимо для обеспечения и защиты общих экономических интересов; б) для защиты конечного потребителя; в) когда меры по государственному регулированию цен соответствуют принципу пропорциональности, четко определены, прозрачны и не носят дискриминационного характера.

Таким образом, Суд ЕС установил ряд критериев, при наличии которых регулируемые цены могут рассматриваться как соответству-

17 Санкции в виде пени, которые может наложить Суд, начисляются ежедневно с момента вынесения решения Судом ЕС и до получения уведомления от государства о том, что имплементация положений 3-го Пакета в национальное законодательство полностью завершена. Размеры санкций зависят от длительности и серьезности нарушения, размера государства и варьируются от 10 тыс. евро до 148 тыс. евро за каждый день!

18 См.: Case № C-265/08 Federutility and others v Autorita per l'energia elettrica e il gas)//доступно на http://curia. europa.eu/juris/liste.jsf?language=en\&num=C-265/08. 
ющие законодательству о едином энергетическом рынке. Однако даже если рассматривать обеспечение защиты интересов конечных потребителей как обоснование для введения государственного регулирования цен, то и тут Суд отмечает, что такие меры должны носить временный характер и применяться только к той потребительской группе, которая нуждается в них больше всего. Таким образом, в каждом конкретном случае государственного вмешательства в ценообразование на энергетическом рынке контрольными органами ЕC (Комиссия и Суд ЕС) будет оцениваться а) соответствие принимаемых мер по государственному регулированию цен на энергию критериям, установленным Судом ЕС, б) их адекватность и пропорциональность. Финальное же решение о правомерности введения этих мер будет принимать Суд ЕС.

Получив такие четкие разъяснения со стороны Суда ЕС, Комиссия инициировала серию новых расследований случаев государственного регулирования цен на энергорынке. Так, совсем недавно, в конце июня 2013г. вышел очередной Пресс-релиз, в котором говорилось, что Комиссия инициировала судебное разбирательство против Польши. Причиной, как выяснилось, послужило невыполнение Польшей положений Газовой директивы ТЭП. Суть нарушений законодательства ЕC со стороны Польши заключалась в том, что, во-первых, Польша вообще не предусмотрела временные пределы для применения государственного регулирования цен и, во-вторых, государственное регулирование цен в Польше применялось не только в отношении домовладельцев, но и всех потребителей, независимо от их положения и ситуации на рынке. Стоит ли отмечать, что процедура расследования против Польши была начата в далёком 2009 году. И ввиду отсутствия со стороны Польши каких-либо действий по устранению выявленных нарушений в вопросе государственного регулирования цен на газ Комиссия была вынуждена обратиться в Суд ЕС ${ }^{19}$.

3. Иные расследования и дела, инициированные Комиссией в отношении государств.

Ряд дел в отношении государств, инициированных Комиссией и рассмотренных Судом ЕС, представляют собой интерес с точки зрения толкования Судом ЕС спорных положений Второго и Третьего энергопакетов и решения вопросов об их соотношении с существующим законодательством Европейского Союза в целом

\footnotetext{
19 См. подробнее: 20/06/2013 Internal gas market: the Commission takes Poland to Court over regulated gas prices for business consumers//доступно на http://ec.europa.eu/ index_en.htm.
}

и фундаментальными свободами внутреннего европейского рынка в частности.

Так, решение Суда ЕС от 22 октября 2013 г. по объединенным делам C-105/12 - C-107/12 по запросу голландского суда касается как раз интерпретации ст. 63 ДФЕС (о свободе движения капитала в рамках ЕС) и ст. 345 ДФЕС (о неприкосновенности права собственности) и их соотношения с положениями Второго и Третьего энергопакетов ${ }^{20}$.

Одно из требований ТЭП - разделение вертикально-интегрированных предприятий, при котором бизнес по управлению сетями (например, сетями передачи электроэнергии, газопроводами) должен быть отделен от бизнеса по производству и продаже энергии конечным потребителям как в вопросах принятия решений, так и на уровне собственности. Согласно этому требованию в национальное законодательство Нидерландов были внесены соответствующие изменения, которые запрещают системному оператору владеть акциями или входить в какую-либо группу компаний, производящих или поставляющих энергию.

Ко времени принятия внутреннего законодательства о разделении вертикально-интегрированных предприятий с точки зрения организационно-правовой формы истцы Essent and others были вертикально интегрированным предприятием, которое занималось производством, поставкой, торговлей электричеством и газом, а также управлением сетями передачи и распределения электроэнергии в Нидерландах. В 2009 г. во исполнение требований национального законодательства о независимости системы эксплуатации сетей компания Essent NV была разделена на 2 отдельные компании, одна из которых занималась эксплуатацией системы распределения энергии и акции которой были переданы государству, а вторая осуществляла деятельность в сфере производства, поставки и торговли энергией. Остальные две компании, входящие в группу, разделены не были, при этом в качестве обоснования был приведен аргумент о том, что операторами сетей распределения энергии будут выступать не сами эти компании, а их дочерние структуры. Суд Нидерландов, рассматривая дело, посчитал, что нормы национального законодательства о запрете приватизации могут противоречить ст. 345 ДФЕС, так как ограничивают частные инвестиции, а положения о запрете вхождения системного оператора в группу лиц могут ограничивать свободу движения капита-

20 См.: Cases C-105/12 to C-107/12//доступно на: http:// curia.europa.eu/juris/document/document.jsf?text=\&doci $\mathrm{d}=143343$ \&pageIndex $=0$ \&doclang $=\mathrm{EN} \& \operatorname{mode}=\mathrm{lst} \& \mathrm{dir}=\&$ occ $=$ first $\&$ part $=1 \&$ cid $=1100100$. 
ла. В связи с этим за разъяснением возникших противоречий нидерландский суд обратился за преюдициальным заключением в Суд ЕС.

Суд, изучив обстоятельства дела и проанализировав соответствующие нормы европейского и голландского законодательства, отметил, что правила о публичной собственности в системе сетей распределения и передачи энергии, так или иначе должны отвечать требованиям о свободном движении капитала. Но в определенных случаях, на которые указал Суд в своем решении, такое ограничение допустимо.

Суд пояснил, что в соответствии со ст. 63 (1) ДФЕС движение капитала подразумевает под собой, в частности, как «прямые» инвестиции, а именно инвестиции в форме долей участия в другом предприятии, что дает возможность эффективного управления и контроля, так и «портфельные» инвестиции, которые означают приобретение акций (долей) компании исключительно с целью сделать финансовое вложение без намерения участвовать в управлении или получить контроль над предприятием. Суд посчитал в данном деле, что запрет на приватизацию, установленный законодательством Нидерландов, препятствует и не допускает ситуации, чтобы акции компании, осуществляющей эксплуатацию сетей, принадлежали частной компании. Государственная монополия на сети распределения и передачи энергии - это безусловная установка ТЭП, которая, вместе с тем, идет вразрез с принципом свободы движения капитала, так как ограничивает производителей и поставщиков из других европейских стран, не говоря уже о неевропейских поставщиках, которые аналогично национальным предприятиям по законодательству Нидерландов не могут приобретать акции компании системного оператора.

Когда эти ограничения свободного движения капитала допустимы? По логике Суда ЕC, такие случаи содержатся в ст. 65 ДФЕС.

В соответствии с устоявшейся практикой Суда ЕС исключительно экономические причины не могут являться основанием, оправдывающим ограничение свободы движения капитала, гарантированной Договором о функционировании ЕС. Но если стоит вопрос о том, что ограничение свободы движения капитала происходит в общих публичных интересах, то такое ограничение допустимо, что тоже подтверждается решениями Суда ЕС. Но вот какой интересный вывод делает Суд - он посчитал, что та борьба, которая ведется с перекрестным субсидированием на национальном уровне в ходе выполнения требований ТЭП необходима а) для обеспечения прозрачности рынков газа и электроэнергии и предотвращения нарушения конкуренции; б) для обеспечения доста- точного притока инвестиций в систему распределения электричества и газа. Поэтому, по логике Суда ЕС, соответствующие меры, принимаемые на национальном уровне, направлены на обеспечение и защиту публичных интересов. Суд обосновывает свой вывод тем, что в Договоре о функционировании ЕС в качестве одного из принципов фигурирует и защита конкуренции в целях обеспечения прав потребителя. Суд также отмечает, что заявленная необходимость увеличения притока инвестиций в энергетический сектор, реализация которого способствует обеспечению безопасности поставок энергии, также направленна на обеспечение публичных интересов.

Таким образом, цели и общий смысл директив как Второго, так и Третьего энергопакетов, среди которых основными являются обеспечение справедливой конкуренции и защита прав потребителя, а также действия, направленные на их реализацию, осуществляются в публичных интересах, что оправдывает возможные ограничения такого принципа, как свободное движение капитала. Однако, делает оговорку Суд, такие ограничения по своему масштабу должны соответствовать тем целям, ради которых они вводятся, т.е. должен соблюдаться принцип пропорциональности.

Думается, что данное решение имеет первостепенное значение в плане толкования ряда фундаментальных положений как ТЭП, так и Договора о функционировании ЕС. Поэтому высказанные Судом позиции будут определять и предрешать исход других дел, касающихся регулирования конкуренции в энергетическом секторе.

Расследования Европейской комиссии в отношении энергетических компаний.

Исключительно важной сферой деятельности Комиссии являются борьба с нарушениями правил конкуренции, в том числе и со злоупотреблением бывшими национальными естественными монополиями своим пока еще доминирующим положением на энергетическом рынке, а также защита прав потребителя.

На сегодняшний день в активе Комиссии находятся дела о нарушении конкурентного права, возбужденные против таких гигантов европейской энергетики, как Distrigas, E.ON, ENI, Gaz de France Suez, RWE. В перечень вменяемых данным компаниям нарушений вошли отказ третьим лицам в доступе к энергетическим сетям, предоставление доступа на дискриминационных условиях, закрытие рынков сбыта для конкурентов, умышленное сдерживание инвестиций в инфраструктуру.

\section{1. Защита прав потребителя.}

Совсем недавно в марте 2013 года Суд ЕС вынес решение, вызвавшее немалый резонанс в 
свете продолжающейся либерализации энергетического рынка. Дело потребительской ассоциации Verbraucherzentrale Nordrhein-Westfalen E.V против компании RWE Vertrieb AG (далее RWE) $)^{21}$ было инициировано в связи с поступившим от немецкого суда запросом по поводу порядка применения к долгосрочным газовым контрактам норм права ЕС, касающихся защиты прав потребителей ${ }^{22}$. Спор между основным поставщиком природного газа населению компанией RWE и потребительской ассоциацией касался правомерности норм внутреннего немецкого законодательства, позволяющих поставщику изменять тарифы на газ в договорах с потребителями в одностороннем порядке, без указания причин, условий и масштаба изменений. Это вылилось в то, что с 1 июля 2003 года по 1 октября 2005 года RWE повысила тарифы на газ примерно в 4 раза! При этом у потребителей (обычное население) в принципе не было возможности сменить поставщика - в отсутствии конкуренции на немецком газовом рынке RWE, будучи монополистом, в полной мере пользовалась сложившейся ситуацией. В связи с этим основным требованием потребительской ассоциации, выступавшей в защиту «пострадавших» потребителей, было требование о компенсации излишне уплаченных сумм за газ за тот самый период повышения тарифов с 2003 по 2005 гг ${ }^{23}$.

Суд ЕС, рассматривая дело, дал однозначную оценку возникшей ситуации, сделав революционный вывод о том, что контракты на поставку газа не представляют собой никакого исключения по сравнению с обычными коммерческими контрактами, и на них, как и на любые другие контракты с потребителями, распространяется действие правил о защите прав потребителей, содержащихся как во внутреннем гражданском законодательстве ФРГ, так и законодательстве ЕС (Директива ЕС 93/13,

21 См.: Дело C-92/11 доступно на: http://curia.europa. eu/juris/document/document.jsf?text=\&docid=135405\&pa geIndex $=0$ \&doclang $=$ EN\&mode $=1$ st $\&$ dir $=\&$ occ $=$ first $\&$ part $=1 \&$ cid $=1084203$.

22 См.: Directive 93/13/EEC of 5 April 1993 on unfair terms in consumer contracts; Directive 2003/55/EC of the European Parliament and of the Council of 26 June 2003 concerning common rules for the internal market in natural gas and repealing Directive 98/30/EC. Доступно на http:// ec.europa.eu/index_en.htm.

23 Немецкие суды высказались в защиту потребителей: в частности, одним из них было принято решение о взыскании с RWE излишне уплаченных по контрактам на поставку газа сумм в размере 16 128,63 евро, однако RWE с таким решением не согласилась и решила его обжаловать. В конечном итоге, Верховный Суд Германии столкнулся при рассмотрении дела с некоторыми сложностями при толковании положений отдельных директив ЕС, в связи с чем и обратился с запросом в суд ЕС. являющаяся основным компонентом системы защиты прав потребителей ЕC).

Таким образом, глобальная направленность позиции Суда вполне понятна. Если ранее газовые контракты расценивались как специфические в силу представления о том, что энергетический рынок - это совершенно особый рынок, на котором должна господствовать естественная монополия, то сейчас такие контракты, как это следует из логики Суда EC, не должны иметь такой специфики, а, следовательно, на них распространяются общие положения внутреннего законодательства о защите прав потребителей, которые не позволяют продавцу/ поставщику необоснованно изменять существенные условия в контрактах с потребителями. Все это свидетельствует о переходе ЕС к здоровой конкуренции на газовом рынке.

В данном деле Суд ЕС также предпринял попытку анализа заключенных газовых контрактов с потребителями и с точки зрения положений газовой директивы 2003/55/EC (далее - Газовая Директива). В рассматриваемой ситуации, когда согласно условиям контракта поставщик оставляет за собой право изменять цены на газ без каких-либо оснований и без определения масштаба изменения цен, при условии, что потребитель будет лишь проинформирован о таком изменении в разумный срок, философия Суда выглядит довольно просто. Отталкиваясь от идеи о том, что потребитель всегда находится в положении более слабом, нежели продавец или поставщик, имея ввиду его крайне незначительную «рыночную силу» и уровень знаний (особенно когда речь идет о поставке газа), Суд подчеркивает, что потребитель, как правило, вынужден всегда соглашаться на условия, предложенные ему продавцом, не имея при этом какой-либо возможности повлиять на содержание контракта. Отсюда и общая направленность законодательства ЕС на защиту потребителя как лица более уязвимого в этой ситуации, из чего, по мнению Суда, и нужно исходить при толковании положений как Директивы 93/13, так и Газовой директивы ${ }^{24}$.

24 В частности, Директива 93/13 запрещает использование тех условий контракта, которые ведут к значительному дисбалансу сторон, ущемляя права потребителя. Кроме того, Директива 93/13 обязывает поставщика излагать контракт понятным и ясным языком, предоставляя потребителю проверить все условия контракта заранее. По мнению Суда ЕС, предоставление потребителю информации о заключаемом контракте ДО момента его непосредственного заключения, имеет определяющее значение для потребителя при принятии решения о заключении контракта. Тем не менее законодатель ЕС обозначил еще большую важность вопросов защиты прав потребителя, приняв Директиву 2003/55, где также подчеркивается необходимость информировать покупателя о заключаемом контракте и его усло- 
Резюмируя, Суд ЕС занял следующую позицию. Признавая в принципе возможность пересмотра тарифов, особенно когда речь идет о долгосрочных контрактах на поставку газа, понимая при этом вполне резонные интересы поставщика в этой ситуации, который и сам покупает газ на оптовом рынке, Суд ЕС заявил, что условия контрактов, которые позволяют изменять тарифы, должны отвечать требованиям прозрачности и добросовестности в отношении прав потребителей. Интересно, что получив разъяснения Суда ЕC, немецкий Федеральный Суд обязал поставщика (RWE) компенсировать истцам (25 потребителям) излишне уплаченные за 2 года деньги в размере 16 128,63 евро. Это еще раз свидетельствует о том, насколько отличается ситуация и статус потребителя в России, где по большому счету выбора у него просто нет, ввиду наличия только одного поставщика газа на все еще монопольном российском рынке и регулирования тарифов на поставку газа правительством, и как укрепились и продолжают усиливаться позиции потребителя на европейском энергетическом рынке.

2. Борьба Комиссии с дискриминацией на энергетическом рынке ЕС.

Борясь с дискриминацией на европейском энергетическом рынке, Комиссия возбудила расследование против компании ОРСОМ, единственного в Румынии оператора по обмену мощностями, и его материнской компании Transelectrica $^{25}$. Нарушение ОРСОМ, по мнению Комиссии, заключалось в требовании ко всем участникам спотового рынка по обмену мощностями быть зарегистрированными на территории Румынии. В мае 2013 года Комиссия высказала свои претензии относительно такого рода деловой практики компаний, назвав еe дискриминационной по национальному признаку и месту регистрации компаний, что, соответственно, нарушает конкурентное законодательство ЕС.

3. Расследования Комиссии в отношении монополистов и компаний, злоупотребляющих доминирующим положением.

Серьезной проблемой для Комиссии остаются бывшие национальные монополисты, которые и после начавшейся либерализации все еще продолжают занимать довольно сильные позиции на рынке. При этом бывшие мо-

виях, имея в виду контракты на поставку газа, где это особенно важно.

25 См.: European Commission Press Release Brussels, 30 May 2013//Antitrust: Commission sends statement of objections to Romanian power exchange ОРСОМ//доступно на http://europa.eu/rapid/press-release_IP-13-486_ en.htm?locale $=$ en нополисты зачастую злоупотребляют своим доминирующим положением для того, чтобы помешать появлению новых участников (конкурентов). Отсюда и предельно жесткие усилия Комиссии по недопущению таких злоупотреблений и повышенные требования к монополистам. Так, в 2010 г. после расследования Комиссии итальянская компания ENI обязалась произвести отчуждение трех принадлежащих ей трансграничных магистральных газопроводов (TAG, TENP, Transitgas), по которым в Италию поступает газ из России (TAG) и Северной Европы (TENP/Transitgas). До этого (в марте 2009 г.) Комиссия уже сделала предупреждение относительно ENI, подозревая, что ENI может злоупотреблять своим доминирующим положением. А отправной причиной спора стало то, что ENI была вертикально интегрированной компанией, которая осуществляла свою деятельность и в сфере транспортировки, и в сфере поставки газа, пытаясь ограничить доступ остальных конкурентов к своим сетям и мощностям и максимально ограничить инвестиции в систему линий электропередачи ${ }^{26}$.

Представители Комиссии ЕС считают, что равный и недискриминационный доступ к инфраструктуре, то есть к трубопроводам - это ключ к объединению газового рынка, ценовой конкуренции, а также к безопасным поставкам газа в рамках всего ЕС. Поэтому подход Комиссии при проведении расследований в отношении бывших и/или действующих монополистов предельно серьезный.

В июле 2011 года Комиссия начала расследование в отношении чешской компании CEZ действующего производителя электричества в Чехии, которая подозревалась в злоупотреблении доминирующим положением на чешском энергетическом рынке. Комиссия предприняла несколько проверок в помещениях компании CEZ в ноябре 2009 г., вменяя в нарушение CEZ то, что злоупотребляя своим доминирующим положением, компания перекрывает доступ на чешский энергетический рынок другим потенциальным конкурентам, следствием чего становится снижение количества инвестиций в этот сектор. Для того, чтобы добровольно устранить эти нарушения, в июне 2012 года CEZ предложила взять на себя ряд обязательств, в том числе отказаться от ряда инфраструктурных объектов по производству угля. В апреле 2013 года эти обязательства стали юридически обязательными. Комиссия посчитала,

26 См.: ENI foreclosure (Case COMP 39.315) Commission Decision of 29 September 2010//доступно на http://ec.europa.eu/competition/antitrast/cases/ dec_docs/39315_3019_9pdf, accessed 11 January 2011: Rod Lambert \& Christopher Reekie (2010). 
что такое решение проблемы будет вполне приемлемым, имея в виду, что потребитель получит выгоду от того, что на чешском рынке в сфере производства и поставки электричества появится компания-конкурент $\mathrm{CEZ}^{27}$.

Таким образом, многие дела, возбужденные Комиссией, не доходят до Суда, так как компании активно используют возможности исправить свои нарушения на стадии общения с Комиссией, принимая на себя устраивающие ее так называемые «проконкурентные» обязательства. Такой вариант дает предприятиям право согласовать с Комиссией суть принимаемых обязательств в обмен на прекращение разбирательств еще до вынесения решений о нарушениях и наложения штрафов.

По состоянию на сегодняшний день Комиссией принято 9 решений о проконкурентных обязательствах в энергетическом секторе. Так, например, показательно расследование Комиссии, начавшееся в 2009 году, по поводу запрета соглашения, касающегося поставки природного газа и предусматривающего раздел рынков между компаниями E.ON и GDF Suez. Tранспортировка газа осуществлялась через трубопровод MEGAL, использовавшийся как канал для передачи газа из России на французский рынок. Расследуя это дело, Комиссия наложила первый штраф за антимонопольное нарушение в энергетическом секторе ${ }^{28}$. Причем сначала Комиссия требовала взыскать в общей сложности штраф в размере 1 млрд евро за длящееся нарушение со стороны компаний, заключивших вышеупомянутое соглашение в далеком 1975 году, когда ими было решено совместно строить газопровод MEGAL через Германию. Это соглашение действовало до 2005 года, и по логике Комиссии, компания GDF Suez занимала монопольное положение на французском газовом рынке на протяжении 5 лет, так как август 2000 был предельным сроком для имплементации положений первой Газовой директивы, ознаменовавшей начало либерализации

27 В 2012 Комиссия возбудила новое расследование касающееся злоупотребления доминирующим положением, против болгарского энергетического холдинга который, якобы, мог злоупотреблять доминирующим положением на оптовом энергетическом рынке Болгарии, устанавливая территориальные ограничения на поставку электричества в соглашениях на поставку. Окончательное решение по делу пока не вынесено// european commission press release brussels, 24 january 2013 internal energy market: commission refers bulgaria estonia and the united kingdom to court for failing to fully transpose eu rules//доступно на: http://europa.eu/rapid/ press-release_ip-13-42_en.htm.

28 Press Release Antitrust 08/07/2009: Commission fines E.ON and GDF Suez $€ 553$ million each for market sharing in French and German gas markets//доступно на сайте: http://www.ec.europa.eu. энергорынка. На немецком газовом рынке, по оценкам Комиссии, нарушения конкуренции продолжались, начиная с 1980 года, когда газопровод MEGAL начал функционировать. После апелляции, поданной компаниями в Суд ЕC, относительно неверной оценки Комиссией длительности нарушения, Суд ЕС сократил размер штрафа для каждой компании до 320 млн евро. Помимо штрафа за нарушение конкуренции на немецком газовом рынке, компания E.ON приняла на себя ряд обязательств ${ }^{29}$, которые должны способствовать повышению доступа на немецкий газовый рынок ${ }^{30}$.

4. Иные расследования Комиссии в отношении компаний.

Интересно отметить, что Комиссия наказывает компании и за препятствования, чинимые ими в проведении антимонопольных расследований. В частности, при проведении одного из расследований в 2012 г., две чешские энергетические компании (ЕРН и EP Investment Advisors) были оштрафованы лишь за то, что ими были нарушены требования ст. 23 Регламента 1/2003 (обязанность предоставить документы сотрудникам Комиссии). В итоге Комиссия наложила штраф на компании в размере 2,5 млн евро, только за то, что во время проверки для проверяющих со стороны Комиссии оказались недоступны личные сообщения электронной почты менеджеров компании, а также произошла утечка входящих сообщений, что помогло скрыть часть сообщений от проверяющих ${ }^{31}$.

В этом же ряду стоит и еще одно дело, в котором Суд ЕС отклонил апелляцию компании E.ON на решение Комиссии и Суда общей юрисдикции о присуждении штрафа в размере 38 млн евро, заявив, что размер штрафа вполне соответствует нарушению, которое было

29 Обязательства, принятые немецкой компанией E.ON, касались следующего: продажа более 20\% своих электрогенерирующих мощностей для стимулирования конкуренции в секторе производства электроэнергии; продажа всех принадлежащих компании высоковольтных электроэнергетических сетей для исключения дискриминации третьих лиц. Продажа должна была осуществляться под надзором доверительного управляющего, а покупатели должны были одобряться Комиссией. Этот случай стал первым в истории применения европейского конкурентного права, когда компания самостоятельно предложила произвести отчуждение крупных инфраструктурных активов.

30 См.: E.ON/GDF (Case COMP/39.401) Summary of Commission Decision of July 2009//доступно на http:// eur-lex.europa.eu/LexUriServ/LexUriServ.do?uri=OJ:C:20 09:248:0005:0006:EN:PDF, accessed 11 January 2011: Rod Lambert \& Christopher Reekie (2010).

31 Commission decision of 28 March 2012 relating to a proceeding under Article 23 of Regulation (EC) No 1/2003 (refusal to submit to an inspection), COMP 39.793, EPH and others; IP/12/319. 
совершено $^{32}$. Именно на таком штрафе настаивала Комиссия, считая срыв в ночное время печати с опечатанного сотрудниками Комиссии помещения компании во время проведения проверки крайне серьезным нарушением, препятствующим проведению расследования по подозрению компании в антиконкурентной практике на немецком энергетическом рынке.

Также стоит упомянуть и начатое в сентябре 2012г. расследование в отношении российской компании ОАО «Газпром», которая подозревается в злоупотреблении своим доминирующим положением и нарушении правил конкуренции на рынке поставок газа в Центральной и Восточной Европе ${ }^{33}$. Ряд комментариев при этом сводится к тому, что расследование против Газпрома носит формальный характер и имеет больше политический подтекст ${ }^{34}$. Однако есть позиция, что рейды Комиссии в офисах компании в Европе будут иметь далеко идущие последствия для российского газового гиганта в общем русле деятельности Комиссии по внедрению конкуренции, защите прав конечного потребителя и созданию единого энергетического рынка ЕС в целом.

Эти решения демонстрируют, что Комиссия, по максимуму используя потенциал конкурентного права и тот инструментарий, который предоставлен ей Регламентом 1/2003, добивается необходимых результатов на пути строительства единого конкурентного энергетического рынка.

\section{Заключение}

Как результат, спустя 20 лет после начала либерализации энергетического рынка, благодаря оперативным и правильным действиям Комиссии во взаимодействии с Судом ЕС были достигнуты значительные успехи.

По данным Комиссии, на сегодняшний день примерно 14 европейских энергокомпаний действуют в более чем одной стране ЕС, и примерно 12 стран-членов ЕС имеют более трех поставщиков энергии. Домохозяйства и малый бизнес могут выбирать между несколькими поставщиками в двух третях стран ЕС. В Бельгии,

32 См.: Press Release No 148/12 22 November 2012/The Court of Justice confirms that E.ON Energie AG must pay a fine of $€ 38$ million for breaking a seal during an inspection relating to a competition law investigation//доступно на: www.curia.europa.eu

33 Case No. 39816: Upstream gas supplies in Central and Eastern Europe, http://ec.europa.eu/competition/elojade/ isef/case_details.cfm?proc_code $=1 \_39816$.

34 См.: Nicolò Sartori 'The European Commission vs. Gazprom: An Issue of Fair Competition or a Foreign Policy Quarrel?'//Instituto Affari Internazionali working papers 13 | 03 - January 2013/ISSN 2280-4331.P3.
Великобритании, Чехии, Ирландии и Испании более $10 \%$ потребителей в 2011 году поменяли поставщиков. С 2000 по 2010 годы количество стран-экспортеров энергоресурсов в Европу увеличилось с 14 до 23. Дополнительно к работе национальных регуляторов стали функционировать общеевропейские структуры ACER (Agency for the Cooperation of Energy Regulators) и CEER (Council of European Energy Regulators), успешно разрабатываются долгосрочные планы развития газовых и энергетических сетей ${ }^{35}$.

Комиссия делает акцент в своих расследованиях и решениях на том, что потребитель должен получать только пользу и выгоду от либерализации энергетического сектора ${ }^{36}$. В связи с чем дальнейшие действия Комиссии против злоупотребления доминирующим положением на рынке и других нарушений, в том числе внезапные проверки (surprise inspections), просто необходимы. Территориально же Комиссия сейчас больше сосредоточена на расследованиях нарушений антимонопольного законодательства в «восточном» направлении ${ }^{37}$.

Как бы то ни было, все еще под вопросом остается возможность создания единого энергетического рынка к 2014 году. По оценкам самой Комиссии: «Довольно много уже достигнуто, продолжающаяся работа должна принести свои плоды совсем скоро» ('Much has already been achieved and ongoing work is expected to bear fruit soon') ${ }^{38}$.

Тем не менее уже сейчас ясно, что справедливая конкуренция на таком чувствительном рынке возможна только путем установления четких и понятных правил для всех стран EC, a также максимально жесткого контроля со стороны Комиссии и Суда ЕС за их выполнением всеми без исключения действующими лицами на этом рынке: государствами (даже самыми большими); бывшими монополистами; новы-

\footnotetext{
Только что утверждена третья редакция десятилетнего плана развития газовой инфраструктуры Европы на 2013-2022 гг. См.: ENTSOG (European Network of transmission system operators for gas), объединение операторов газовых сетей EC, ENTSO-e (European Network of transmission system operators for electricity), объединение европейских операторов электросетей. См. подробнее: Мельникова С. И. Два года сомнительного существования Третьего Энергопакета ЕС//доступно на: http:// www.eriras.ru/files/s-melnikova-dva-goda-somnitelnogosushhestvovaniya-tretego-energopaketa-es.pdf.
}

36 См.: DG Competition Management Plan 2012, р4//доступно на: http://www.ec.europa.eu.

37 См.: Report from the Commission on Competition Policy 2012, COM (2013) 257 final, p7.

38 Cм.: Communication from the Commission to the European Parliament, the Council, the European Economic and Social Committee and the Committee of the Regions, COM (2012) 663 final, p3 and 5. 
ми игроками на энергетическом рынке, а также - компаниями из третьих стран.

И если российские компании по-прежнему хотят оставаться на этом крайне привлека- тельном рынке, то им нужно понять и принять логику Третьего энергопакета, а также побудительные мотивы действий Комиссии и Суда ЕC.

\section{Библиография}

1. Исполинов А.С., Двенадцатова Т.И. Создание единого энергетического рынка в ЕС: тихая революция с громкими последствиями // Балтийский регион. - 2013. - №2. URL:http:// cyberleninka.ru/article/n/sozdanie-edinogo-energeticheskogo-rynka-es-tihaya-revolyutsiya-sgromkimi-posledstviyami.

2. Мельникова С. И. Два года сомнительного существования Третьего Энергопакета ЕС// http://www.eriras.ru/files/s-melnikova-dva-goda-somnitelnogo-sushhestvovaniya-tretegoenergopaketa-es.pdf.01

3. Nicolò Sartori 'The European Commission vs. Gazprom: An Issue of Fair Competition or a Foreign Policy Quarrel?'//Instituto Affari Internazionali working papers 13 | 03 - January 2013/ISSN 2280-4331

\section{References}

1. Ispolinov A.S., Dvenadtsatova T.I. Sozdanie edinogo energeticheskogo rynka v ES: tikhaya revolyutsiya s gromkimi posledstviyami // Baltiiskii region. - 2013. - №2. URL:http://cyberleninka. ru/article/n/sozdanie-edinogo-energeticheskogo-rynka-es-tihaya-revolyutsiya-s-gromkimiposledstviyami.

2. Mel'nikova S.I. Dva goda somnitel'nogo sushchestvovaniya Tret'ego Energopaketa ES//http://www. eriras.ru/files/s-melnikova-dva-goda-somnitelnogo-sushhestvovaniya-tretego-energopaketa-es. pdf.01

3. Nicolò Sartori 'The European Commission vs. Gazprom: An Issue of Fair Competition or a Foreign Policy Quarrel?'//Instituto Affari Internazionali working papers 13 | 03 - January 2013/ISSN 2280-4331 